\title{
Characterization of a High Strength Weld Metal for TRIP Steels Using EBSD and HAADF/STEM Imaging
}

\author{
Badri K Narayanan^*, Marie A Quintana^, Michael J Mills** \\ * Department of Materials Science and Engineering, The Ohio State University, Columbus, OH \\ 43210. \\ $\wedge$ The Lincoln Electric Company, Cleveland, OH 44117.
}

Transformation Induced Plasticity (TRIP) steels have a three phase microstructure comprised of ferrite, bainite and retained austenite. The transformation of retained austenite to martensite during forming improves the uniform elongation of the material [1]. A self-shielded arc welding process (FCAW-S) [2] provides a unique solution to weld TRIP steels. A Fe-0.2\%C-1.0\%Al-1.0\% $\mathrm{Si}-1.7 \% \mathrm{Ni}$ steel weld was deposited in a $\mathrm{V}$-groove and samples were taken from the as-welded region. We have performed microstructural characterization of this weld intended to mimic TRIP steels compositionally and microstructurally with the goal of achieving a combination of high strength $(>700 \mathrm{MPa})$ and ductility.

The as-welded microstructure is predominantly bainitic ferrite and retained austenite. An XL-30 ESEM equipped with a FEG source and a TSL electron backscatter pattern and phase identification system was used for characterizing the dual-phase microstructure (Figure 1a). There is significant heterogeneity even within the same parent austenitic grain with a mixture of carbide free bainite and acicular ferritic laths with large misorientations. The orientation relationship (O.R) between the bainite and the retained austenite was close to Kurudjmov-Sachs/ Nishiyama-Wassermann (K-S/NW) O.R with all the variants possessing a small misorientation from the $\{001\} \gamma$ zones. The orientation of the retained austenite and its orientation relationship with the ferrite variants are shown in Figure 1b. Figure 2 shows the presence of ferrite and retained austenite in a phase map superimposed with an image quality map that outlines the bainitic lath boundaries.

High angle annular dark field (HAADF) and bright field scanning transmission electron microscopy (STEM) techniques were used to characterize the morphology of the retained austenitic regions and precipitation within the ferritic laths. The retained austenite shows two morphological variants. There are films of retained austenite between the bainitic laths and small patches of austenite at prior austenitic grain boundaries and in regions between packets of bainite. Energy dispersive spectroscopy (EDS) line profiles across the ferrite/austenite/ferrite regions did not show any evidence for segregation of substitutional alloying additions. However the austenite regions showed significant enrichment in carbon confirmed through X-ray diffraction and Electron energy loss spectroscopy (EELS). There was no evidence for cementite precipitation within the bainitic laths or in the retained austenitic regions.

Twinned martensitic regions related by a rotation of $71^{\circ}$ about the $<110>$ axes and lath martensitic domains are seen within the retained austenitic regions. The edge-on orientation of martensitic laths confirms a N-W orientation relationship with the austenite. The trace of the martensitic laths is along the close packed $\{111\}$ slip planes of the parent austenite. The $\gamma / \alpha$ inter-phase boundaries possess a jagged morphology with heavy dislocation content in the untransformed austenite at these boundaries. Cementite precipitation is seen within some of the martensite laths. The orientation 
relationship of the carbides to the martensite was consistent with a Bagaryatskii OR for cementite in tempered martensite. There was no evidence found for any carbide precipitation within the bainitic laths or in the retained austenitic regions.

\section{References}

1. De Cooman, B.C., Current Opinion in Solid State \& Materials Science, 2004. 8(3-4): p. 285303.

2. Bonisewiski, T., Self-Shielded Arc Welding. 1992, Abington Publishing, Cambridge, England.
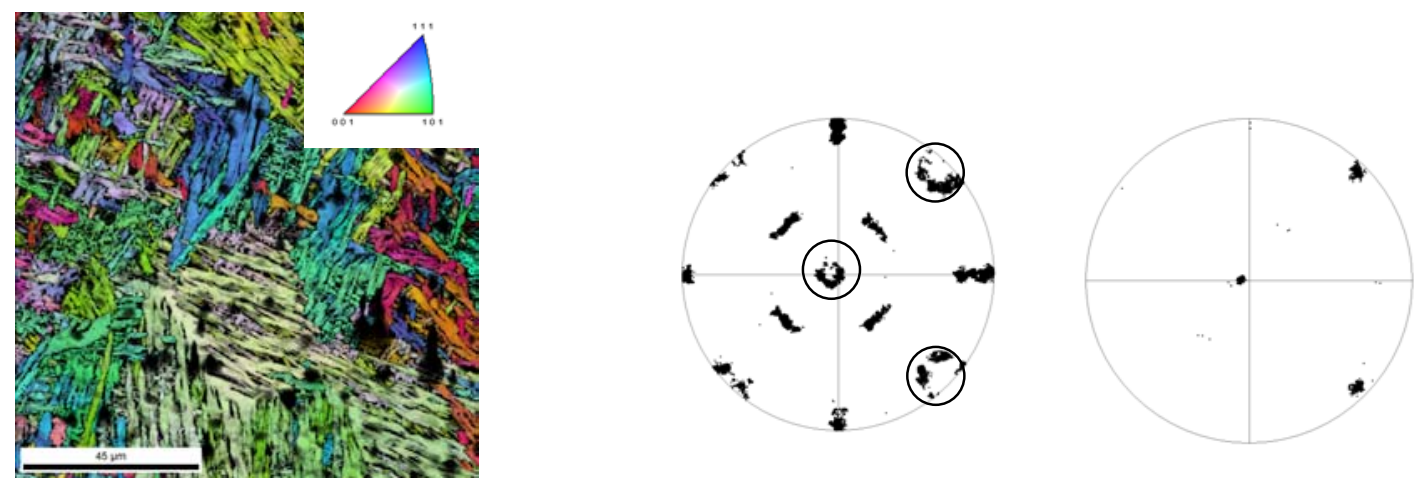

Figure 1: (a) Inverse pole figure of the weld microstructure showing bainitic ferrite with highly misoriented acicular ferritic laths. (b) Pole figures showing variant distribution of the ferritic laths within one prior austenitic grain along with pole figure of the retained austenite regions

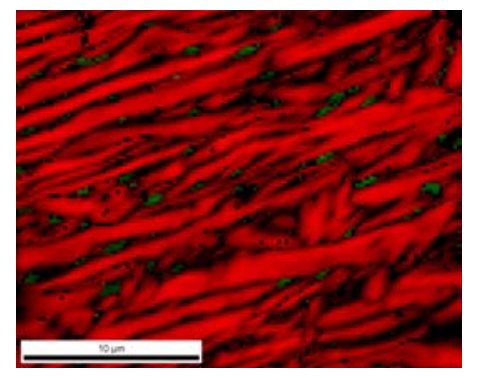

Figure2. Phase map of a bainitic packet (red) with retained austenite (green) in between the laths

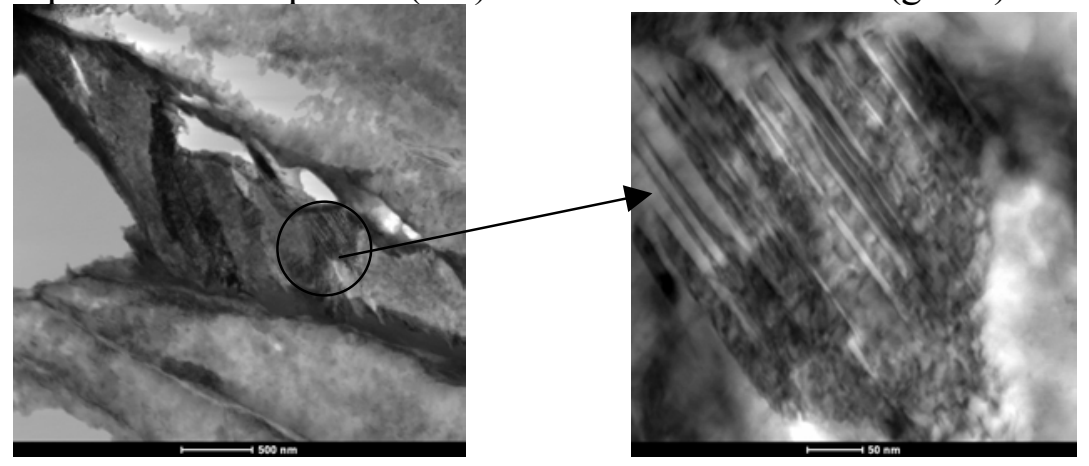

Figure 3 (a). Bright field STEM images of a blocky austenitic region that has transformed into packets of lath martensite. (b) Twinned martensitic regions were seen within the retained austenite. 